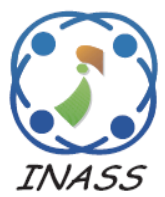

\title{
Dual-Phase Parasitism SOS with Crossover Operator for Optimal Multi Single-Phase DG in Unbalance Distribution System
}

\author{
Umar Umar ${ }^{1,2 *} \quad$ Faanzir Faanzir $^{1,2} \quad$ Firdaus Firdaus $^{1} \quad$ Indri Suryawati $^{1}$ \\ Muhira Dzar Faraby ${ }^{1} \quad$ Adi Soeprijanto $^{1} \quad$ Ontoseno Penangsang $^{1}$ \\ ${ }^{1}$ Department of Electrical Engineering, Institut Teknologi Sepuluh Nopember, Surabaya 60111, Indonesia \\ ${ }^{2}$ Department of Electrical Engineering, Universitas Khairun, Ternate 79362, Indonesia \\ * Corresponding author's Email: umarmadjid94@gmail.com
}

\begin{abstract}
The interconnection of single-phase households DG into the existing grid requires appropriate anticipation to ensure the quality and reliability of the existing system. This paper deals with the optimal placement and sizing of multi single-phase DG in unbalanced distribution systems for power loss reduction and voltage improvement while maintaining voltage unbalance and harmonic are in the acceptable limit. Optimal location and sizing of DG are determined simultaneously using the improvement version of Symbiotic Organisms Search (SOS), called Dual-Phase Parasitism SOS (DPP-SOS) with a crossover operator. DPP-SOS consists of original parasitism (OP) and random weight parasitism (RWP). DPP-SOS was programmed using MATLAB software and validated using 26 benchmark functions. To demonstrate the effectiveness of this method in reducing losses, the DPP-SOS is also tested using 7, and 25 bus test systems. Result show that DPP-SOS with a crossover operator has been successful in determining the location and rating of single-phase and three-phases DG simultaneously. DPP-SOS has an average convergence speed of $24.08 \%$ faster than the basic SOS. The simulation result also shows that multi single-phase DG is effective in reducing power loss, increasing voltage, and reducing voltage unbalance in the distribution system.
\end{abstract}

Keywords: Crossover operator, Dual-phase parasitism, Random weight parasitism, Single-phase DG, Voltage unbalance.

\section{Introduction}

The new paradigm in power system management causes ownership of power plants is no longer a monopoly. Individuals or communities can have their own generators and share or sell excess energy to the local grid. DG in the power system can be used to minimize power losses $[1,2]$, improve voltage profiles [2], and minimize cost [3]. Almost all research on DG integration into power systems is performed with a balanced system approach $[2,3]$. The distribution system is essentially an unbalanced three-phase system [4]. Simplifying the unbalanced system into a balanced system does not describe the actual system. A large load imbalance in the distribution system leads to overheating, harmonics and performance disruption to equipment with a three-phase supply [5].
Finding the appropriate location and size of DG has received significant attention from engineers. In the last two decades, various methods have emerged such as: loss-voltage sensitivity index (LVSI) [6], power stability index (PSI) [7], and voltage stability index [8]. Determination of the optimal location and size based on the index methods is usually for single-objective problems that contain few variables. These methods will have difficulty or even cannot be used in solving multi-objective problems involving many variables, especially for nondifferentiable functions [9].

The limitations of analytical methods in solving non-differentiable problems promote the development of heuristic methods. The no free lunch (NFL) theory suggests that no single heuristic method can handle all optimization problems [10]. NFL theory opens up opportunities for engineers to 
improve existing methods, or even find new heuristic methods. SOS is one of the algorithms that has received significant attention from engineers [11] because it is simple, has few parameters so that it is easy to apply to various problems [12].

Although SOS is considered a robust algorithm [12-14], several studies have shown that this algorithm is also not free from shortcomings. Sharhan and Omran [15] showed that the process of updating organisms using the best organism in the mutualism and commensalism phases will quickly affect all organisms in the ecosystem. As a result, the variability of organisms is low which leads to premature convergence. Random selection of organisms allows the organisms to be selected incorrectly. Organisms with very high fitness may be selected in the parasitism phase, making it impossible to replace them with new individuals. This condition can reduce the variability of organisms in the ecosystem [16]. Another problem with SOS is the imbalance between exploration and exploitation [17-19] and inefficient computational time $[17,19,20]$.

Various attempts have been performed to improve the performance of SOS. Improved SOS based on ring propagation is proposed in [15] to increase the variability of organisms. Grouping, assignment and ranking methods are proposed in [16]. The organism with the best fitness was selected for the commensalism phase, while the organism with the worst fitness was selected to perform parasitism. Adaptive Benefit Factor (ABF) and modification of the parasitism phase is proposed in [17] to ensure a balance between exploration and exploitation of SOS. Modifications to the parasitism phase were proposed in [18] to maintain the variability of the organism so that the global optimum is achieved. The parasitism phase is divided into two groups with a probability of 0.5 . The parasitism vector was determined based on quasi opposite based learning (QOBL). Modifications to the phases of mutualism, commensalism, and parasitism are proposed in [19]. In the mutualism phase, the same benefit factor (BF) is used for each organism. The random coefficient on the mutualism phase is narrowed in the range of 0.4 to 0.9 , while the parasitism phase is omitted to simplify the algorithm. The integration of chaotic local search (CLS) [20] and quasi-oppositional [21] were proposed to ensure the achievement of a global optimum and speed up the computation time. Random walk and adaptive Cauchy mutation methods are proposed in [22].

Based on the research, the parasitism phase is a crucial part in improving the performance of the
SOS algorithm [16-18]. This research is an improved version of SOS by modifying the parasitism phase called dual-phase parasitism SOS (DPP-SOS). The parasitism phase is separated into two sub-phases, namely original parasitism (OP) and random weight parasitism (RWP). DPP is used to increase the variability of organisms by exploring $50 \%$ of the new organisms produced by RWP. The contributions of this paper are: 1. Using DPP-SOS to refine the performance of basic SOS. 2. Using a crossover operator, so that the optimal location and sizing of DG can be set simultaneously. 3. Optimization using multi single-phase DG and comparing it with three-phase DG. 4. Optimization using a multi-objective function consisting of power loss, voltage deviation, harmonics, and PVUR.

The rest of this paper is organized as follows: Section 2 explained SOS and DPP-SOS in detail. The DPP-SOS validation using the benchmark function and single-phase DG optimization are presented in Section 3. Conclusions and future research are presented in Section 4.

\section{Methodology}

\subsection{SOS algorithm}

The Symbiotic organisms search (SOS) algorithm was introduced in 2014. The SOS algorithm imitates the symbiotic relationship of living things in their environment which is called an ecosystem [12]. The random relationship of living things as a strategy for survival is described in mutualism, commensalism, and parasitism. The mutualism phase shows the relationship of organisms $\left(X_{i}\right.$ and $\left.X_{k}\right)$ that are mutually beneficial. The new organisms resulting from these interactions are defined as [12]:

$$
\begin{aligned}
& X_{\text {iNew }}=X_{i}+\operatorname{rand}(0,1) \times\left(X_{\text {best }}-\alpha \times B f_{1}\right) \\
& \left.X_{\text {kNew }}=X_{k}+\operatorname{rand}(0,1) \times X_{\text {best }}-\alpha \times B f_{2}\right)
\end{aligned}
$$

Where $i$ and $k$ are integers $1,2,3 \ldots X_{\text {best }}$ is the organism with the best fitness in the ecosystem. $\alpha$ is a mutual vector, which is formulated as [12]:

$$
\alpha=\frac{X_{i}+X_{k}}{2}
$$

$B f_{1}$ and $B f_{2}$ are benefit factors. Benefit factors are defined as follows:

$$
B f_{1}=1+\operatorname{round}(\operatorname{rand}(0,1))
$$




$$
B f_{2}=1+\operatorname{round}(\operatorname{rand}(0,1))
$$

In the commensalism phase, $X_{i}$ tries to benefit from the interaction with the $X_{k}$ organism. The new organisms produced in the commensalism phase can be defined as follows [12]:

$$
X_{\text {iNew }}=X_{i}+\operatorname{rand}(-1,1) \times\left(X_{\text {best }}-X_{k}\right)
$$

The parasitism phase describes a symbiotic relationship, where one organism is benefits and the other is harmed. Suppose $X_{i}$ is trying to take advantage of organism $X_{k}$. Organism $X_{i}$ makes a clone of itself called the parasitic vector (PV). If the parasitic vector's fitness is higher than $X_{k}$, then $X_{k}$ will be replaced by a parasitic vector, and vice versa.

\subsection{DPP-SOS algorithm}

Maintaining a balance between exploration and exploitation of organisms plays a very important role in achieving the global optimum. In the SOS algorithm, the process of exploitation of organisms is determined in the mutualism and commensalism phase, while the exploration of organisms is determined in the parasitism phase. In the parasitism phase, most of the new organisms are removed from the population because their fitness values are lower. The organisms that dominate the ecosystem are new organisms with high fitness. As a result, the variability of organisms is low. The search space for new organisms only moves on organisms with a high fitness level. This condition allows the SOS algorithm to achieve premature convergence. To improve the variability of organisms, the parasitism phase is divided into two sub-phases, namely original parasitism (OP) and random weight parasitism (RWP). OP is the same parasitism as basic SOS, while RWP is parasitism that uses a modified random weight of the crow search algorithm (CSA) which is defined as follows:

$$
R W=\operatorname{rand}(0,1) \times \operatorname{rand}(-2,2)
$$

Using Eq. (7), the new organism position in the parasitism phase is formulated as follows:

$$
X_{\text {iNew }}=X_{i}+R W \times\left(X_{\text {best }}-X_{i}\right)
$$

The DPP in the parasitism phase allows the algorithm to expand the search space and avoid population concentration, by offering half of the new organisms from the RWP. The flowchart of DPP-SOS is shown in Fig. 1.

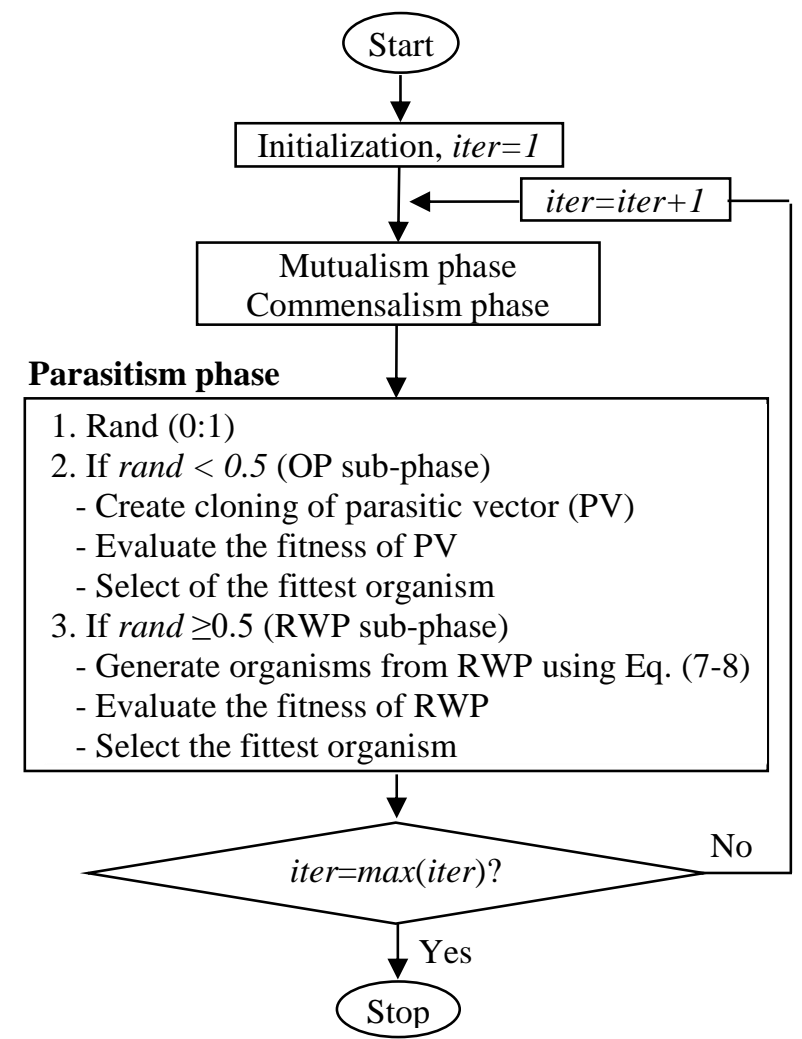

Figure. 1 DPP-SOS flowchart

\section{DPP-SOS validation}

Validation was performed to see the performance of the DPP-SOS algorithm compared to several algorithms in the literature. In this paper, the test will be carried out using 26 standard mathematical functions and two problems in the field of electrical engineering.

\subsection{Mathematical benchmark functions}

The performance of DPP-SOS is tested using the benchmark function, which consists of 26 standard mathematical functions [12]. The simulation results are then compared with GA, Bees Algorithm (BA), PSO, SOS, Quasi-Oppositional SOS (QOSOS), and Chaotic SOS (CSOS). DPP-SOS is built using MATLAB and runs on a laptop with a Core 2 processor and 2 GB RAM. The parameters used by DPP-SOS and SOS are: ecosystem number $=50$; Maximum number of iteration $=3000$; Maximum error $=1 \times 10^{-12}$. Parameter settings of GA, BA, and PSO follow [12]. Parameter settings of QOSOS follow [21], while CSOS parameters follow [20]. The mean (M) and iteration average (Avg_iter) of basic SOS and DPP-SOS are determined after the program is run 25 times for each benchmark function. Values less than $1 \times 10^{-12}$ are considered equal to 0 [12]. Table 1 shows the performance of 
DPP-SOS in solving 26 benchmark functions compared to other algorithms. Boldface numbers indicate the best value for each benchmark.

Table 1. DPP-SOS performance compared to other algorithms

\begin{tabular}{|c|c|c|c|c|c|c|c|c|c|}
\hline Function & Min & Description & GA [12] & PSO [12] & BA [12] & SOS [23] & QOSOS [21] & CSOS [20] & DPP-SOS \\
\hline \multirow[t]{2}{*}{ Beale } & \multirow[t]{2}{*}{0.00} & $\mathrm{M}$ & 0.00 & 0.00 & $1.88 \mathrm{E}-5$ & 0.00 & 0.00 & 0.00 & 0.00 \\
\hline & & Avg_iter & $\mathrm{Na}$ & $\mathrm{Na}$ & $\mathrm{Na}$ & 52.92 & $\mathrm{Na}$ & $\mathrm{Na}$ & 28.76 \\
\hline \multirow[t]{2}{*}{ Easom } & \multirow[t]{2}{*}{-1.00} & $\mathrm{M}$ & -1.00 & -1.00 & -0.99994 & -1.00 & -1.00 & -1.00 & -1.00 \\
\hline & & Avg_iter & $\mathrm{Na}$ & $\mathrm{Na}$ & $\mathrm{Na}$ & 56.24 & $\mathrm{Na}$ & $\mathrm{Na}$ & 34.12 \\
\hline \multirow[t]{2}{*}{ Matyas } & \multirow[t]{2}{*}{0.00} & $\mathrm{M}$ & 0.00 & 0.00 & 0.00 & 0.00 & 0.00 & 0.00 & 0.00 \\
\hline & & Avg_iter & $\mathrm{Na}$ & $\mathrm{Na}$ & $\mathrm{Na}$ & 23.64 & $\mathrm{Na}$ & $\mathrm{Na}$ & 16.44 \\
\hline \multirow{2}{*}{$\begin{array}{l}\text { Boha- } \\
\text { chevsky } 1\end{array}$} & \multirow[t]{2}{*}{0.00} & $\mathrm{M}$ & 0.00 & 0.00 & 0.00 & 0.00 & 0.00 & 0.00 & 0.00 \\
\hline & & Avg_iter & $\mathrm{Na}$ & $\mathrm{Na}$ & $\mathrm{Na}$ & 24.88 & $\mathrm{Na}$ & $\mathrm{Na}$ & 18.8 \\
\hline \multirow[t]{2}{*}{ Booth } & \multirow[t]{2}{*}{0.00} & $\mathrm{M}$ & 0.00 & 0.00 & $5.3 \mathrm{E}-4$ & 0.00 & 0.00 & 0.00 & 0.00 \\
\hline & & Avg_iter & $\mathrm{Na}$ & $\mathrm{Na}$ & $\mathrm{Na}$ & 88.28 & $\mathrm{Na}$ & $\mathrm{Na}$ & 73.2 \\
\hline \multirow{2}{*}{$\begin{array}{l}\text { Micha- } \\
\text { lewicz } 2\end{array}$} & \multirow[t]{2}{*}{-1.8013} & $\mathrm{M}$ & -1.8013 & -1.57287 & -1.8013 & -1.8013 & -1.8013 & -1.8013 & -1.8013 \\
\hline & & Avg_iter & $\mathrm{Na}$ & $\mathrm{Na}$ & $\mathrm{Na}$ & 14.96 & $\mathrm{Na}$ & $\mathrm{Na}$ & 10.68 \\
\hline \multirow[t]{2}{*}{ Schaffer } & \multirow[t]{2}{*}{0.00} & $\mathrm{M}$ & 0.00424 & 0.00 & 0.00 & 0.00 & 0.00 & 0.00 & 0.00 \\
\hline & & Avg_iter & $\mathrm{Na}$ & $\mathrm{Na}$ & $\mathrm{Na}$ & 99.92 & $\mathrm{Na}$ & $\mathrm{Na}$ & 48.8 \\
\hline \multirow{2}{*}{\begin{tabular}{l|} 
Six Hump \\
Camel Back
\end{tabular}} & \multirow{2}{*}{-1.03163} & $\mathrm{M}$ & -1.03163 & -1.03163 & -1.03163 & -1.03163 & -1.03163 & -1.03163 & -1.03163 \\
\hline & & Avg_iter & $\mathrm{Na}$ & $\mathrm{Na}$ & $\mathrm{Na}$ & 47.88 & $\mathrm{Na}$ & $\mathrm{Na}$ & 36.84 \\
\hline \multirow{2}{*}{$\begin{array}{l}\text { Boha- } \\
\text { chevsky } 2\end{array}$} & \multirow[t]{2}{*}{0.00} & $\mathrm{M}$ & 0.06829 & 0.00 & 0.00 & 0.00 & 0.00 & 0.00 & 0.00 \\
\hline & & Avg_iter & $\mathrm{Na}$ & $\mathrm{Na}$ & $\mathrm{Na}$ & 22.8 & $\mathrm{Na}$ & $\mathrm{Na}$ & 16.72 \\
\hline Boha- & 0.00 & $\mathrm{M}$ & 0.00 & 0.00 & 0.00 & 0.00 & 0.00 & 0.00 & 0.00 \\
\hline chevsky 3 & & Avg_iter & $\mathrm{Na}$ & $\mathrm{Na}$ & $\mathrm{Na}$ & 32.2 & $\mathrm{Na}$ & $\mathrm{Na}$ & 22.12 \\
\hline Schubert & -186.73 & $\mathrm{M}$ & -186.73 & -186.73 & -186.73 & -186.73 & -186.73 & -186.73 & -186.73 \\
\hline & & Avg_iter & $\mathrm{Na}$ & $\mathrm{Na}$ & $\mathrm{Na}$ & 144.32 & $\mathrm{Na}$ & $\mathrm{Na}$ & 94.76 \\
\hline Colville & 0.00 & $\mathrm{M}$ & 0.01494 & 0.00 & 1.11760 & 0.00 & 0.00 & 0.00 & 0.00 \\
\hline & & Avg_iter & $\mathrm{Na}$ & $\mathrm{Na}$ & $\mathrm{Na}$ & 1325.76 & $\mathrm{Na}$ & $\mathrm{Na}$ & 105.44 \\
\hline Micha- & -4.6877 & $\mathrm{M}$ & -4.64483 & -2.49087 & -4.6877 & -4.6877 & -4.68348 & -4.6877 & -4.6877 \\
\hline lewicz 5 & & Avg_iter & $\mathrm{Na}$ & $\mathrm{Na}$ & $\mathrm{Na}$ & 127.44 & $\mathrm{Na}$ & $\mathrm{Na}$ & 92.36 \\
\hline Zakharov & 0.00 & $\mathrm{M}$ & 0.01336 & 0.00 & 0.00 & 0.00 & 0.00 & 0.00 & 0.00 \\
\hline & & Avg_iter & $\mathrm{Na}$ & $\mathrm{Na}$ & $\mathrm{Na}$ & 75.56 & $\mathrm{Na}$ & $\mathrm{Na}$ & 56.32 \\
\hline Micha- & -9.6602 & $\mathrm{M}$ & -9.49683 & -4.00718 & -9.6602 & -9.6602 & -9.6595 & -9.6602 & -9.6602 \\
\hline lewicz 10 & & Avg_iter & $\mathrm{Na}$ & $\mathrm{Na}$ & $\mathrm{Na}$ & 1394.2 & $\mathrm{Na}$ & $\mathrm{Na}$ & 976.88 \\
\hline Step & 0.00 & $\mathrm{M}$ & $1.17 \mathrm{E}+03$ & 0.00 & 5.12370 & 0.00 & 0.00 & 0.00 & 0.00 \\
\hline & & Avg_iter & $\mathrm{Na}$ & $\mathrm{Na}$ & $\mathrm{Na}$ & 184.8 & $\mathrm{Na}$ & $\mathrm{Na}$ & 167.12 \\
\hline Sphere & 0.00 & $\mathrm{M}$ & $1.11 \mathrm{E}+03$ & 0.00 & 0.00 & 0.00 & 0.00 & 0.00 & 0.00 \\
\hline & & Avg_iter & $\mathrm{Na}$ & $\mathrm{Na}$ & $\mathrm{Na}$ & 60.08 & $\mathrm{Na}$ & $\mathrm{Na}$ & 49.88 \\
\hline Sum & 0.00 & $\mathrm{M}$ & $1.48 \mathrm{E}+2$ & 0.00 & 0.00 & 0.00 & 0.00 & 0.00 & 0.00 \\
\hline squares & & Avg_iter & $\mathrm{Na}$ & $\mathrm{Na}$ & \begin{tabular}{|l|}
$\mathrm{Na}$ \\
\end{tabular} & 56.8 & $\mathrm{Na}$ & $\mathrm{Na}$ & 47.4 \\
\hline Quartic & 0.00 & $\mathrm{M}$ & 0.18070 & 0.00116 & \begin{tabular}{|l|}
$1.72 \mathrm{E}-6$ \\
\end{tabular} & $7.415 \mathrm{E}-05$ & $3.2708 \mathrm{E}-5$ & $2.480 \mathrm{E}-5$ & 5.894E-05 \\
\hline & & Avg_iter & $\mathrm{Na}$ & $\mathrm{Na}$ & $\mathrm{Na}$ & 3000 & $\mathrm{Na}$ & $\mathrm{Na}$ & 3000 \\
\hline Schwefel & 0.00 & $\mathrm{M}$ & 11.0214 & 0.00 & 0.00 & 0.00 & 0.00 & 0.00 & 0.00 \\
\hline 2.22 & & Avg_iter & $\mathrm{Na}$ & $\mathrm{Na}$ & $\mathrm{Na}$ & 101.08 & $\mathrm{Na}$ & $\mathrm{Na}$ & 84.52 \\
\hline Schwefel & 0.00 & $\mathrm{M}$ & $7.40 \mathrm{E}+3$ & 0.00 & 0.00 & 0.00 & 0.00 & 0.00 & $\mathbf{0 . 0 0}$ \\
\hline & & Avg_iter & $\mathrm{Na}$ & $\mathrm{Na}$ & $\mathrm{Na}$ & 63.96 & $\mathrm{Na}$ & $\mathrm{Na}$ & 54 \\
\hline Rosenbrok & 0.00 & $\mathrm{M}$ & $1.96 \mathrm{E}+5$ & 15.08862 & 28.834 & 0.27004 & 1.0354 & 0.4208 & 0.00 \\
\hline & & Avg_iter & $\mathrm{Na}$ & $\mathrm{Na}$ & $\mathrm{Na}$ & 3000 & $\mathrm{Na}$ & $\mathrm{Na}$ & 1825.04 \\
\hline Dixon- & 0.00 & $\mathrm{M}$ & $1.22 \mathrm{E}+3$ & 0.6667 & 0.6667 & 0.6667 & 0.00 & 0.6667 & 0.6667 \\
\hline Price & & Avg_iter & $\mathrm{Na}$ & $\mathrm{Na}$ & $\mathrm{Na}$ & 3000 & $\mathrm{Na}$ & $\mathrm{Na}$ & 3000 \\
\hline Rastrigin & 0.00 & $\mathrm{M}$ & 52.92259 & 43.97714 & 0.00 & 0.00 & 0.00 & 0.00 & 0.00 \\
\hline & & Avg_iter & $\mathrm{Na}$ & $\mathrm{Na}$ & $\mathrm{Na}$ & 93.48 & $\mathrm{Na}$ & $\mathrm{Na}$ & 66.04 \\
\hline Griewank & 0.00 & $\mathrm{M}$ & 10.63346 & 0.01739 & 0.00 & 0.00 & 0.00 & 0.00 & 0.00 \\
\hline & & Avg_iter & $\mathrm{Na}$ & $\mathrm{Na}$ & $\mathrm{Na}$ & 62.04 & $\mathrm{Na}$ & $\mathrm{Na}$ & 51.48 \\
\hline Ackley 26 & 0.00 & $\mathrm{M}$ & 14.67178 & 0.16462 & 0.00 & 0.00 & 0.00 & 0.00 & 0.00 \\
\hline & & Avg_iter & $\mathrm{Na}$ & $\mathrm{Na}$ & $\mathrm{Na}$ & 99.08 & $\mathrm{Na}$ & $\mathrm{Na}$ & 83.00 \\
\hline
\end{tabular}

Na: Not available. 
Table 1 show that DPP-SOS has a better level of convergence than GA, PSO, BA, SOS, QOSOS, and CSOS. DPP-SOS can converge on 24 benchmark functions, while SOS, QOSOS, and CSOS converge only on 23 benchmark functions. BA converges on 18 benchmark functions, while PSO only converges on 17 benchmark functions. GA has the worst level of convergence compared to PSO, BA, SOS, QOSOS, CSOS, and DPP-SOS. GA only converges on 9 of the 26 benchmark functions. Based on the level of convergence speed, DPP-SOS excels in all benchmark functions compared to basic SOS. DPPSOS has an average convergence speed of $24.08 \%$ faster than the basic SOS.

The process of updating SOS organisms in the parasitism phase by replacing low fitness organisms with high fitness organisms causes all organisms with low fitness to be eliminated from the ecosystem. Ecosystems are quickly filled with organisms with high fitness. The parasitism phase-only explores the high fitness organisms. The variability of organisms in the ecosystem is low. The integration of DPPSOS in the parasitism phase increases the variability of organisms in the ecosystem by offering about half of the new organisms derived from RWP. The exploration process in the parasitism phase is not only on high fitness organisms but also new organisms from RWP. This improvement increases the convergence level of DPP-SOS.

\subsection{Single-phase DG optimization on unbalanced sistribution system}

Single-phase DG optimization is applied to an unbalanced distribution system using 7 and 25 bus test systems. The performance of single-phase DG in PVUR mitigation is then compared with threephase DG. Location and phase are included as part of the organism in the DPP-SOS, so that size and location optimization can be performed simultaneously. Crossover operators are used in DPP-SOS to provide a variation on location and phase variables in organisms.

\subsubsection{Crossover operator based DPP-SOS}

Determination of the location and size of DG using SOS is generally performed separately [14, 23]. The location is determined using the sensitivity factor (SF) while the size is determined using the SOS. The SF value is obtained through repeated load flows which take a long time and a lot of energy. The use of DP-SOS with a crossover operator is intended to provide organism variability when location and phase variables are included in the DPP-SOS algorithm. Optimal location and sizing of DG are performed simultaneously, resulting in faster computation times.

In this scheme, organisms in the ecosystem are represented by strings of size, location, and phase. The size string contains a random number representing the DG capacity. The location string contains numbers indicating the location of DG, while the phase strings consist of the numbers 1,2 , or 3 indicating phases $\mathrm{A}, \mathrm{B}$, and $\mathrm{C}$. If $\mathrm{n}$ is the numbers of $\mathrm{DG}$, then the organisms $(X)$ in the ecosystem are written as follows:

$X=$

$\left[x_{1}, x_{2}, \ldots x_{n} ; \operatorname{loc}_{1}, \operatorname{loc}_{2}, \ldots \operatorname{loc}_{n} ; p h_{1}, p h_{2}, \ldots p h_{n}\right](9)$

$x_{1}, x_{2}, \ldots, x_{n}$ are the capacity of DG. $l o c_{1}, l o c_{2}, \ldots l o c_{n}$ are locations of DG, while $p h_{1}, h_{2}, \ldots p h_{n}$ are the phases of DG. The crossover operator is applied to the parasitism phase to obtain the variation of organisms in the location and phase strings. The process of updating the rating string follows the process that generally applies to the SOS algorithm.

\subsubsection{Objectives functions}

The objective of this paper is to reduce power loss while maintaining the bus voltage, harmonics and voltage unbalance to acceptable limits.

a. Active power loss.

The active power loss in the distribution system is determined by the current and line resistance. The line current is determined by the magnitude of the load, while the line resistance is determined by many factors, such as length, diameter, and distribution line material. The objective function related to power loss can be formulated as follows:

$$
F_{1}=\min \left(\frac{P_{D G}}{P_{o}}\right)
$$

$P_{o}$ and $P_{D G}$ are power loss before and after DG installation respectively.

b. Bus Voltage

The bus voltage on each bus must be at $1 \pm 5 \%$ pu. Objective function related to bus voltage, can be written as follows:

$$
F_{2}=\prod_{i=1}^{n b u s} N V S_{i}
$$

$N V S_{i}$ is the bus voltage violation rate of bus i, which is formulated as follows:

$$
N V S_{i}=\left\{\begin{array}{c}
1 \text { if } 0.95 \leq V_{i} \leq 1.05 \\
\exp \left(\mu\left|1-V_{i}\right|\right), \text { for other } V_{i}
\end{array}\right.
$$


$V i$ is voltage at bus i. $\mu$ is weight factor. In this paper $\mu=3$.

c. Voltage unbalance

The imbalance in the distribution system is caused by the unbalanced voltage of each phase or the unequal angle difference between the phases or a combination of both. Voltage imbalance in the power system can be determined using several definitions such as voltage unbalance factor (VUF) and phase voltage unbalance rate (PVUR) [24]. VUR is a true voltage unbalance because it takes into account the magnitude and phase angle. The use of VUR is more difficult because it involves positive and negative sequences [25], while the calculation of PVUR is simpler so it is widely used [25]. Moreover, for imbalances below 5\%, the difference between PVUR and VUR is very small $(0.8 \%)$ and has no significant effect [26]. PVUR is defined as follows [25]:

$$
\begin{aligned}
& P V U R= \\
& \max \left(\left|V_{A}-V_{a v}^{P}\right|,\left|V_{B}-V_{a v}^{P}\right|,\left|V_{C}-V_{a v}^{P}\right|\right) \times \frac{100 \%}{V_{a v}^{P}}
\end{aligned}
$$

$V_{A}, V_{B}, V_{C}$ are phase voltage, while $V_{a v}^{P}$ is the average phase voltage. Based on the IEEE standard 141 1993, the maximum voltage unbalance is $2 \%$. To keep the PVUR below $2 \%$, the PVUR is included as the objective function.

$$
F_{3}=\prod_{i=1}^{n b u s} N P V U R_{i}
$$

$N P V U R_{i}$ is the voltage unbalance violation rate of bus $\mathrm{i}$, which is formulated as follows:

$$
N P V U R_{i}=\left\{\begin{array}{c}
1 \text { if } P V U R_{i} \leq 2 \\
\exp \left(\frac{P V U R_{i}}{2}\right)^{0.8}, \text { if } P V U R_{i}>2
\end{array}\right.
$$

$P V U R_{i}$ is phase voltage unbalance rate at bus $\mathrm{i}$.

d. Harmonics

Based on the IEEE-519 standard, individual harmonic distortion (iHD) and total harmonic distortion (THD) should not exceed 3\% and 5\% respectively. The individual and total harmonic distortion violation levels are formulated below:

$$
N i H D_{i}=\left\{\begin{array}{c}
1 \text { if } i H D_{i} \leq 3 \\
\exp \left(\frac{i H D_{i}}{3}\right)^{0.8}, \text { if } i H D_{i}>3
\end{array}\right.
$$

$$
N T H D_{i}=\left\{\begin{array}{c}
1 \text { if } T H D_{i} \leq 5 \\
\exp \left(\frac{T H D_{i}}{5}\right)^{0.8}, \text { if } T H D_{i}>5
\end{array}\right.
$$

$N i H D_{i}$ and $N T H D_{i}$ are individual and total harmonic distortion violation level at bus $\mathrm{i}$. $T H D_{i}$ and $i H D_{i}$ are total and individual harmonic distortion at bus i respectively. The objective function related to harmonics can be calculated using the following equation:

$$
F_{4}=\prod_{i=1}^{n b u s} N i H D_{i} \times \prod_{i=1}^{n b u s} N T H D_{i}
$$

The objective function in this paper is formulated in the following equation:

$$
F=w_{1} F_{1}+w_{2} F_{2}+w_{3} F_{3}+w_{4} F_{4}
$$

$w_{1}, w_{2}, w_{3}$, and $w_{4}$ are weight factors.

\subsubsection{Data test system}

The performance of DPP-SOS will be tested using two data test systems, namely system 7 [27] and 25 bus test system [28]. Several adjustments have been performed to the load data to suit the purpose of this paper.

The 7-bus test system is not a real-world system. Lines 1-2, 2-3, 2-5, and 5-6 are three-phase lines. Line 6-7 is a double phase, while line 3-4 is a single phase. The total load connected to the 7 bus test systems is 5,603 MW and 1,425MVar. Three-phase nonlinear loads are assumed to be connected to buses 3,5 , and 6 . All loads are supplied from the infinitive bus on bus 1 . The loads data are presented in Table 2, while lines data are presented in [28]. Harmonics injection data are presented in Table 3 [29].

The 25-bus test system consists of 24 branches and 25 buses. The total load connected to the 25 bus test systems is $3.5399 \mathrm{MW}$ and $2.393 \mathrm{MVar}$. The harmonic sources are considered to be connected to buses $12,15,19,22$, and 25 . The entire load is supplied by bus 1 , which is the only source for this system. All lines on the 25 bus test systems are three-phase systems. Load data is shown in table 4, while lines data are presented in [28].

\subsubsection{Optimal single-phase DG on 7 bus test system}

Optimization of the location and DG sizing in this paper is performed simultaneously using singlephase DG and then compared with three-phase DG with the same capacity. The DG used is the DG which only supplies real power. The maximum DG capacity is $250 \mathrm{~kW}$ for single-phase DG and 750 
Table 2. Load data of 7 bus test system

\begin{tabular}{|c|c|c|c|}
\hline No Bus & Sa (kVA) & Sb (kVA) & Sc (kVA) \\
\hline 1 & 0 & 0 & 0 \\
\hline 2 & $360+\mathrm{j} 70$ & $432+\mathrm{j} 50$ & $120+\mathrm{j} 30$ \\
\hline 3 & $145+\mathrm{j} 10$ & $643+\mathrm{j} 100$ & $445+\mathrm{j} 76$ \\
\hline 4 & $145+\mathrm{j} 28$ & & \\
\hline 5 & $732+\mathrm{j} 112$ & $345+\mathrm{j} 98$ & $225+\mathrm{j} 63$ \\
\hline 6 & $432+\mathrm{j} 82$ & $377+\mathrm{j} 93$ & $425+\mathrm{j} 103$ \\
\hline 7 & & $132+\mathrm{j} 312$ & $645+\mathrm{j} 198$ \\
\hline
\end{tabular}

Table 3. Harmonic sources

\begin{tabular}{|l|c|c|c|c|}
\hline Order & 5 & 7 & 11 & 13 \\
\hline Magnitude & 23,52 & 6,08 & 4,57 & 4,2 \\
\hline Degree & 111 & 109 & -158 & -178 \\
\hline
\end{tabular}

Table 4. Load data of 25 bus test system

\begin{tabular}{|c|c|c|c|}
\hline No Bus & Sa $(\mathbf{k V A})$ & Sb $(\mathbf{k V A})$ & Sc $(\mathbf{k V A})$ \\
\hline 1 & 0 & 0 & 0 \\
\hline 2 & 0 & 0 & 0 \\
\hline 3 & $35+\mathrm{j} 25$ & $40+\mathrm{j} 30$ & $45+\mathrm{j} 32$ \\
\hline 4 & $50+\mathrm{j} 40$ & $60+\mathrm{j} 45$ & $50+\mathrm{j} 35$ \\
\hline 5 & $40+\mathrm{j} 30$ & $40+\mathrm{j} 30$ & $40+\mathrm{j} 30$ \\
\hline 6 & $40+\mathrm{j} 30$ & $45+\mathrm{j} 32$ & $35+\mathrm{j} 25$ \\
\hline 7 & 0 & 0 & 0 \\
\hline 8 & $40+\mathrm{j} 30$ & $40+\mathrm{j} 30$ & $40+\mathrm{j} 30$ \\
\hline 9 & $60+\mathrm{j} 45$ & $50+\mathrm{j} 40$ & $50+\mathrm{j} 35$ \\
\hline 10 & $35+\mathrm{j} 25$ & $40+\mathrm{j} 30$ & $45+\mathrm{j} 32$ \\
\hline 11 & $45+\mathrm{j} 32$ & $35+\mathrm{j} 25$ & $40+\mathrm{j} 30$ \\
\hline 12 & $250+\mathrm{j} 35$ & $60+\mathrm{j} 45$ & $50+\mathrm{j} 40$ \\
\hline 13 & $135+\mathrm{j} 25$ & $45+\mathrm{j} 32$ & $40+\mathrm{j} 30$ \\
\hline 14 & $50+\mathrm{j} 35$ & $50+\mathrm{j} 40$ & $60+\mathrm{j} 45$ \\
\hline 15 & $133.3+\mathrm{j} 100$ & $133.3+\mathrm{j} 100$ & $133.3+\mathrm{j} 100$ \\
\hline 16 & $40+\mathrm{j} 30$ & $40+\mathrm{j} 30$ & $40+\mathrm{j} 30$ \\
\hline 17 & $40+\mathrm{j} 30$ & $35+\mathrm{j} 25$ & $45+\mathrm{j} 32$ \\
\hline 18 & $40+\mathrm{j} 30$ & $40+\mathrm{j} 30$ & $40+\mathrm{j} 30$ \\
\hline 19 & $35+\mathrm{j} 25$ & $40+\mathrm{j} 30$ & $45+\mathrm{j} 32$ \\
\hline 20 & $60+\mathrm{j} 45$ & $50+\mathrm{j} 35$ & $50+\mathrm{j} 40$ \\
\hline 21 & $40+\mathrm{j} 30$ & $35+\mathrm{j} 25$ & $45+\mathrm{j} 32$ \\
\hline 22 & $50+\mathrm{j} 35$ & $60+\mathrm{j} 45$ & $50+\mathrm{j} 40$ \\
\hline 23 & $60+\mathrm{j} 45$ & $50+\mathrm{j} 40$ & $50+\mathrm{j} 35$ \\
\hline 24 & $35+\mathrm{j} 25$ & $45+\mathrm{j} 32$ & $40+\mathrm{j} 30$ \\
\hline 25 & $60+\mathrm{j} 25$ & $50+\mathrm{j} 30$ & $50+\mathrm{j} 35$ \\
\hline
\end{tabular}

$\mathrm{kW}$ for three-phase DG. The parameter settings for DPP-SOS are: number of ecosystems $=20$ and maximum iteration $=150$.

The optimal results of single-phase DG placement on the 7-bus test system are shown in Table 5. Table 5 shows that in the base case, the voltage on each bus meets the requirements of $1 \pm 5 \%$ pu. The minimum voltage is 0.955 on bus7c. THD on each bus is below 5\%. The largest THD is $4.66 \%$ on bus 6a, while the average THD is $2.32 \%$.
Maximum PVUR is $2.04 \%$ on bus 6. Maximum PVUR exceeds the IEEE 141 standard. The total active and reactive power losses are $85.86 \mathrm{~kW}$ and 259.71 kVAR, respectively.

At a penetration level of $22.77 \%$, the optimal location of the 6 DG single-phase is on bus 6 and bus 7 with details: $2 \times 0.25 \mathrm{MW}$ on bus $6 \mathrm{a} ; 0.25 \mathrm{MW}$ on bus $6 \mathrm{~b}$ and $3 \times 0.25 \mathrm{MW}$ on bus 7c. Single-phase DG injection on bus 6 and bus 7 of $1.5 \mathrm{MW}$ reduced active power loss by $56.18 \%$ and reactive power loss by $56.05 \%$. The deviation of the mean bus voltage increased from 0.987 to $0.99 \mathrm{pu}$ and the minimum bus voltage also increased from 0.955 to $0.968 \mathrm{pu}$. An increase in the voltage on each bus is also accompanied by an improvement in THD. The maximum and average THD are decreased by $22.1 \%$ and $24.57 \%$, respectively. THD and individual harmonics are below the standard limits. The placement of 6 DG single-phase has a significant effect on decreasing PVUR. PVUR decreased from $2.04 \%$ in the base case to $1.12 \%$ in the $6 \mathrm{DG}$ singlephase scheme. Power injection using 2 DG threephase also results in reduced power losses, increased bus voltage, and decreased THD, although these improvements are below the performance of the single-phase DG scheme. Injection of 2 DG threephase actually worsens PVUR. PVUR increased from $2.04 \%$ in the base case to $2.09 \%$. The $2 \mathrm{DG}$ three-phase injection scheme at a penetration rate of $22.77 \%$ does not meet the IEEE 141 standard criteria.

At a penetration level of $40.16 \%$, placement 9 DG single-phase reduces power loss and THD, improves the voltage profile, and reduces PVUR. The power loss and maximum PVUR decreased significantly, $69.06 \%$ and $49.73 \%$ respectively, while the average bus voltage increased from 0.987 $\mathrm{pu}$ in the base case, to $0.991 \mathrm{pu}$ in the 9 DG singlephase scheme. The DG injection scheme using 3 DG three-phase shows that although this scheme can reduce power loss and THD, the PVUR is still above the IEEE 141 standard. Three-phase DG injection on bus 6 , resulted in an increase in PVUR. The PVUR increased from $2.04 \%$ to $2.12 \%$.

\subsubsection{Optimal single-phase DG on 25 bus test system}

In this section, the performance of single-phase and three-phase DG will be tested in an unbalanced distribution system with a three-phase line system. The results of single and three-phase DG optimization are shown in Table 6.

Table 6 shows that for the base case, the minimum bus voltage, PVUR, and maximum THD are out of the limits. Power injection using $6 \mathrm{DG}$ 
Table 5. Optimal single and three-phase DG on 7 bus test system

\begin{tabular}{|c|c|c|c|c|c|c|c|c|c|c|}
\hline \multirow{2}{*}{$\begin{array}{l}\text { Penetra- } \\
\operatorname{tion}(\%)\end{array}$} & \multirow[t]{2}{*}{ Scheme } & \multirow[t]{2}{*}{ Location } & \multirow{2}{*}{ Size (MW) } & \multicolumn{2}{|c|}{ Voltage (PU) } & \multirow{2}{*}{$\begin{array}{l}\text { Ploss } \\
(\mathbf{k W})\end{array}$} & \multicolumn{2}{|c|}{ PVUR (\%) } & \multicolumn{2}{|c|}{ THD (\%) } \\
\hline & & & & Min & Mean & & Max & Mean & Max & Mean \\
\hline & Base Case & - & - & 0.955 & 0.987 & 85.86 & 2.04 & 0.69 & 4.66 & 2.32 \\
\hline \multirow{3}{*}{22.77} & $6 \times 1 \phi D G$ & $6 a, 6 a, 6 b$ & $0.25,0.25,0.25$ & 0.968 & 0.990 & 37.62 & 1.12 & 0.39 & 3.63 & 1.75 \\
\hline & & $7 \mathrm{c}, 7 \mathrm{c}, 7 \mathrm{c}$ & $0.25,0.25,0.25$ & & & & & & & \\
\hline & $2 \times 3 \phi D G$ & 6,6 & $0.75, \quad 0.75$ & 0.962 & 0.989 & 43.94 & 2.09 & 0.14 & 2.70 & 1.33 \\
\hline \multirow{4}{*}{40.16} & & $5 a, 6 a, 6 a$ & $0.25,0.25,0.25$ & 0.974 & 0.991 & 26.10 & 1.03 & 0.38 & 2.69 & 1.52 \\
\hline & $9 \times 1 \phi D G$ & $6 b, 6 c, 7 b$ & $0.25,0.25,0.25$ & & & & & & & \\
\hline & & $7 \mathrm{c}, 7 \mathrm{c}, 7 \mathrm{c}$ & $0.25,0.25,0.25$ & & & & & & & \\
\hline & $3 \times 3 \phi$ DG & $6,6,6$ & $0.75,0.75,0.75$ & 0.964 & 0.990 & 32.88 & 2.12 & 0.75 & 2.26 & 1.14 \\
\hline
\end{tabular}

Table 6. Optimal single and three-phase DG on 25 bus test system

\begin{tabular}{|c|c|c|c|c|c|c|c|c|c|c|}
\hline \multirow{2}{*}{$\begin{array}{l}\text { Penetra- } \\
\text { tion(\%) }\end{array}$} & \multirow{2}{*}{ Scheme } & \multirow{2}{*}{ Location } & \multirow{2}{*}{ Size (MW) } & \multicolumn{2}{|c|}{ Voltage (PU) } & \multirow{2}{*}{$\begin{array}{l}\text { Ploss } \\
(\mathbf{k W})\end{array}$} & \multicolumn{2}{|c|}{ PVUR (\%) } & \multicolumn{2}{|c|}{ THD (\%) } \\
\hline & & & & Min & Mean & & Max & Mean & Max & Mean \\
\hline & Base Case & - & - & 0.894 & 0.948 & 195.29 & 2.86 & 0.41 & 6.97 & 2.32 \\
\hline \multirow{3}{*}{42.37} & \multirow{2}{*}{$6 \times$ DG $1 \phi$} & $12 \mathrm{a}, 12 \mathrm{~b}, 13 \mathrm{a}$ & $0.25,0.22,0.25$ & \multirow[t]{2}{*}{0.950} & \multirow[t]{2}{*}{0.965} & \multirow[t]{2}{*}{91.49} & \multirow[t]{2}{*}{0.76} & \multirow[t]{2}{*}{0.09} & \multirow[t]{2}{*}{3.05} & \multirow[t]{2}{*}{1.70} \\
\hline & & $14 \mathrm{~b}, 10 \mathrm{c}, 12 \mathrm{a}$ & $0.24,0,250.25$ & & & & & & & \\
\hline & $2 \times$ DG $3 \phi$ & 12,13 & $0.75,0.75$ & 0.945 & 0.966 & 103.87 & 2.12 & 0.31 & 3.61 & 1.44 \\
\hline \multirow{4}{*}{63.56} & \multirow{3}{*}{$9 \times \mathrm{DG} 1 \phi$} & $11 \mathrm{c}, 12 \mathrm{a}, 12 \mathrm{~b}$ & $0.25,0.25,0.25$ & \multirow[t]{3}{*}{0.958} & \multirow[t]{3}{*}{0.971} & \multirow[t]{3}{*}{71.22} & \multirow[t]{3}{*}{0.73} & \multirow[t]{3}{*}{0.15} & \multirow[t]{3}{*}{2.40} & \multirow[t]{3}{*}{1.30} \\
\hline & & $13 a, 14 b, 15 a$ & $0.25,0.25,0.25$ & & & & & & & \\
\hline & & $15 c, 18 c, 23 b$ & $0.25,0.25,0.25$ & & & & & & & \\
\hline & $3 \times$ DG $3 \phi$ & $11,12,15$ & $0.75,0.717,0.75$ & 0.959 & 0.973 & 86.32 & 1.99 & 0.28 & 2.72 & 1.36 \\
\hline
\end{tabular}

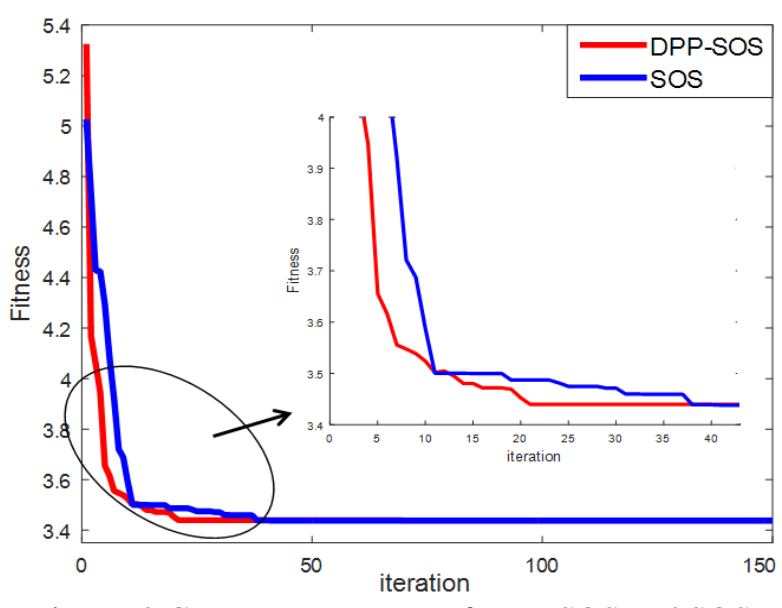

Figure. 2 Curve convergence of DPP-SOS and SOS

single-phase can increase voltage, reduce power loss, PVUR, and THD. Bus voltage, THD and PVUR are at the specified limit. Injection of 9 DG single-phase increases the bus voltage, reduces power loss, PVUR, and THD significantly. This scheme meets the voltage, PVUR and THD standards.

Power injection uses 2 DG three-phase, cannot meet all the standards limit. The bus voltage and PVUR are out of the voltage and PVUR standard limit. The injection uses 3 three-phase DG with a penetration level of $63.56 \%$ meets all standards limit, although its performance is still below the 9 DG single-phase scheme with the same penetration level.

For the convergence speed, optimization using DPP-SOS is faster than using basic SOS. DPP-SOS can increase the variability of organisms in the parasitism phase, so the ecosystems are not only dominated by organisms with high fitness but there are $50 \%$ new organisms from RWP. This improvement increases the performance of DPPSOS compared to basic SOS. The convergence curve of DPP-SOS and SOS is shown in Fig. 2.

\section{Conclusions}

This study discusses the optimal placement and sizing of multiple single-phase DG in unbalanced distribution system using DPP-SOS equipped with a crossover operator. The validation results using the benchmark function show that DPP-SOS is superior to other algorithms, even with basic SOS. DPP-SOS can converge on 24 of 26 benchmark functions with an average convergence speed of $24.08 \%$ faster than basic SOS. The simulation results using the 7 and 25 bus test systems show that DPP-SOS with a crossover operator has been successful in determining the location and rating of single-phase and three-phase DG simultaneously. Multi single- 
phase DG is effective in overcoming the problem of voltage imbalance in the distribution system compared to three-phase DG with the same capacity.

For future research, it will be interesting to compare the performance of several SOS variants. The implementation of DPP-SOS in the field of electrical engineering will still be the focus of further research.

\section{Conflicts of Interest}

This article has not been published and is not under consideration for publication elsewhere. All authors have read and approved the manuscript and take full responsibility for its content. The authors have no conflict of interest in regard to this research or its funding.

\section{Author Contributions}

Conceptualization, Umar Umar; methodology, Umar Umar; software, Umar Umar, Faanzir Faanzir and Indri Suryawati; validation, Umar Umar and Muhira Dzar Faraby; formal analysis, Umar Umar, Indri Suryawati and, Firdaus Firdaus; data curation, Firdaus Firdaus and Faanzir Faanzir; writingoriginal draft preparation, Umar Umar; writingreview and editing, Umar Umar, Ontoseno Penangsang, and Adi Soeprijanto; supervision, Ontoseno Penangsang, and Adi Soeprijanto;

\section{Acknowledgments}

Thank you to the Government of the Republic of Indonesia for financial support through BPP-DN Scholarship to pursue the Doctoral Program at the Department of Electrical Engineering, Institut Teknologi Sepuluh Nopember, Indonesia. The author also thanks anonymous reviewers for their valuable comments and suggestions.

\section{References}

[1] T. Prasetyo, S. Sarjiya, and L. M. Putranto, "Optimal Sizing and Siting of PV-Based DG for Losses Minimization of Distribution using Flower Pollination Algorithm", In: Proc. of International Conference on Information and Communications Technology, pp. 779-783, 2019.

[2] P. Prakash, "Optimal DG Allocation Using PSO", In: Proc. of International Conference on Artificial Intelligence and Smart Systems, pp. 940-944, 2021.

[3] Umar, Firdaus, A. Soeprijanto, and O. Penangsang, "Optimal Expenditure and Benefit Cost Based Location, Size and Type of DGs in
Microgrids Systems Using Adaptive Real Coding Genetic Algorithm", Telkomnika, Vol. 16, No. 1, pp. 10-17, 2018.

[4] D. B. Prakash and C. Lakshminarayana, "Multiple DG Placements in Distribution System for Power Loss Reduction Using PSO Algorithm", In: Proc. of the First Global Colloquium on Recent Advancements and Effectual Researches in Engineering, Science and Technology, Vol. 25, pp. 785-792, 2016.

[5] P. U. Reddy, S. Sivanagaraju, and P. Sangameswararaju, "Power Flow Analysis of Three Phase Unbalanced Radial Distribution System”, International Journal of Advances in Engineering and Technology, Vol. 3, No. 1, pp. 514-524, 2015.

[6] K. B. J. Anuradha, U. Jayatunga, and H. Y. R. Perera, "Voltage-Loss Sensitivity Based Approach for Optimal DG Placement in Distribution Networks", In: Proc. of $14^{\text {th }}$ Conference on Industrial and Information Systems, pp. 553-558, 2019.

[7] A. Amin, S. Kamel, and J. Yu, "Developed Analytical Technique for Optimal Placement and Sizing of DG and DSTATCOM in Radial Distribution Systems", In: Proc. of Twentieth International Middle East Power Systems Conference, pp. 1087-1091, 2018.

[8] R. S and A. N. V, "Analytical Approach for Multiple PV Placements in Radial Distribution System under Balanced and Unbalanced Load Condition", In: Proc. of 5th International Conference on Intelligent Computing and Control Systems, pp. 677-681, 2021.

[9] K. H. Truong, P. Nallagownden, Z. Baharudin, and D. N. Vo, "A Quasi-Oppositional-Chaotic Symbiotic Organisms Search Algorithm for Global Optimization Problems", Applied Soft Computing, Vol. 77, pp. 567-583, 2019.

[10] D. H. Wolpert and W. G. Macready, "No Free Lunch Theorems for Optimization", IEEE Transaction Evolution Computing, Vol. 1, pp. 67-82, 1997.

[11] A. E. Ezugwu and D. Prayogo, "Symbiotic Organisms Search Algorithm: Theory, Recent Advances and Applications", Expert Systems with Applications, Vol. 119, pp. 184-209, 2018.

[12] M. Y. Cheng and D. Prayogo, "Organisms Search: A New Metaheuristic Optimization Algorithm", Computers and Structures, Vol. 139, pp. 98-112, 2014.

[13] B. Das, V. Mukherjee, and D. Das, "DG Placement in Radial Distribution Network by Symbiotic Organisms Search Algorithm for 
Real Power Loss Minimization", Applied Soft Computing, Vol. 49, pp. 920-936, 2016.

[14] G. Setyawan, Umar, A. Soeprijanto, and O. Penangsang, "Symbiotic Organism Search for Sizing and Optimal Location of Distributed Generation Using Novel Sensitivity Factor", In: Proc. of IOP Conference Series: Materials Science and Engineering, Vol. 588, pp. 1-7, 2019.

[15] S. A. Sharhan and M. G. H. Othman, "An Enhanced Symbiosis Organisms Search Algorithm: An Empirical Study", Neural Computing and Applications, Vol. 29, No. 11, pp. 1025-1043, 2016.

[16] L. R. Rodrigues, J. P. P. Gomes, A. R. R. Neto, and A. H. Souza, "A Modified Symbiotic Organisms Search Algorithm Applied to Flow Shop Scheduling Problems", In: Proc. of IEEE Congress on Evolutionary Computation, pp. 17, 2018.

[17] S. Kumar, G. G. Tejani, and S. Mirjalili, "Modified Symbiotic Organisms Search for Structural Optimization", Engineering with Computers, Vol. 35, pp. 1269-1296, 2019.

[18] E. Celik, "A Powerful Variant of Symbiotic Organisms Search Algorithm for Global Optimization", Engineering Applications of Artificial Intelligence, Vol. 87, pp. 1-14, 2020.

[19] D. T. T. Do and J. Lee, "A Modified Symbiotic Organisms Search Algorithm for Optimization of Pin-Jointed Structures", Applied Soft Computing, Vol. 61, pp. 683-699, 2017.

[20] S. Saha and V. Mukherjee, "A Novel ChaosIntegrated Symbiotic Organisms Search Algorithm for Global Optimization", Soft Computing, Vol. 22, pp. 3797-3816, 2018.

[21] S. Nama and A. K. Saha, "An Ensemble Symbiosis Organisms Search Algorithm and its Application to Real World Problems", Decision Science Letters, Vol. 7, No. 2, pp. 103-118, 2018.

[22] F. Miao, L. Yao, and X. Zhao, "Symbiotic Organisms Search Algorithm Using Random Walk and Adaptive Cauchy Mutation on The Feature Selection of Sleep Staging", Expert Systems with Applications, Vol. 176, pp. 114887-114904, 2021.

[23] U. Umar, G. Setyawan, F. Faanzir, F. Firdaus, A. Soeprijanto, and O. Penangsang, "New Enhanced Symbiotic Organisms Search for Optimal Location and Sizing of Disributed Generation in Radial Distribution System", International Journal of Intelligent Engineering and Systems, Vol. 13, No. 5, pp. 170-180, 2020, doi: 10.22266/ijies2020.1031.16.
[24] K. Girigoudar, D. K. Molzahn, and L. A. Roald, "On the Relationships among Different Voltage Unbalance Definitions", 2019 North American Power Symposium, pp. 1-6, 2019.

[25] T. H. Chen, C. H. Yang, and N. C. Yang, "Examination of the Definitions of Voltage Unbalance", International Journal of Electrical Power \& Energy Systems, Vol. 49. pp. 380-385, 2013.

[26] P. Pillary and P. Manyange, "Definition of Voltage Unbalance", IEEE Power Electrical Review, Vol. 21, No. 5, pp. 49-51, 2001.

[27] J. H. Teng, S. H. Liao, and R. C. Leou, "ThreePhase Harmonic Analysis Method for Unbalanced Distribution Systems", Energies, Vol. 7, pp. 365-384, 2014.

[28] J. B. V. Subrahmanyam and C. Radhakrishna, Distributed Generator Placement and Sizing in Unbalanced Radial Distribution System", International Journal of Electrical Power and Energy Systems Engineering, Vol. 2, pp. 232239, 2009.

[29] A. A. Abdelsalam, A. Zidan, and E. E. Saadany, "Optimal DG Allocation in Radial Distribution System with High Penetration of Non-Linier Loads", Electric Power Components and Systems, Vol. 43, No. 13, pp. 1487-1497, 2015. 